\title{
TOWARDS SMART RIYADH: RIYADH WIKI INFORMATION AND COMPLAINING SYSTEM
}

\author{
Eman Al Helal and Hala Mokhtar \\ College of Computer and Information Sciences, King Saud University, KSA, Riyadh
}

\begin{abstract}
In the past ten years, the role of citizens to achieve smart city vision is realized and the people-centric Smart City model has been stressed. In this paper, we propose "Riyadh Wiki Information and Complaining System" for citizen engagement in Riyadh city in Saudi Arabia. The system follows the crowd sourcing approach by allowing citizens to act as sources of data to support the government and to improve their city. It also follows the co-design approach by being an open source platform that allows citizens to cooperate to build the system and add new services. The system aims at enhancing citizens' life and solving governmental issues like transparency, trust, decision-making, and accountability in a cheap way. It is developed as a web-based wiki system, so it can be used easily by the non-skilled citizens while allowing skilled citizens to add new features, functionalities, and new services. It supports both Arabic and English languages and exploits the widespread of social media to attract more citizens. Initial evaluations using eparticipation assessment, web accessibility and web usability evaluation techniques have been carried out and the results show the effectiveness of the system.
\end{abstract}

\section{KEYWORDS}

Smart city, Engagement model, Wiki system, Complaint system, Crowd sourcing, Riyadh.

\section{INTRODUCTION}

Smart city is one of the hot topics that attracts much interest from both academic and business fields. There is no unified definition for a smart city but it has several components including Smart Economy, Smart Citizens, Smart Governance, Smart Mobility, Smart Environment and Smart Living [1]. Smart city concept aims at improving the conditions and the environments for the citizens to have better life.

This paper focuses on the role of smart citizens to support smart government and to achieve smart city vision. In general, governments face many challenges including the transparency between the government and the citizens, the trust of citizens on the government, the decision-making process, and the accountability. Solving such issues is very expensive and needs much efforts and resources.

Citizens' engagement can enhance the quality of services provided by the government, and reduce the costs and burdens of infrastructures. Engagements of citizens is defined as [2]: "the process of informing residents, getting them excited and involved, and then participating in the smart city programmes from early stage of design to implementation and expansion". There are different ways for citizens' engagement. They can volunteer on developing initiatives to their cities, participate on the improvement of the available services by providing their insights and/or 
International Journal of Managing Information Technology (IJMIT) Vol.10, No.2, May 2018

feedback. They can also act as sensors and provide data for the government as they can capture any issue in the city using their smartphones and report it to the government [3]. Co-design, coproduction, co-decision, co-creation, co-evaluation, are different notions of engagement, andeach one of them named by the role of citizen in this cooperation [4].

The solutions proposed by the citizens are based mainly on the web tools and Smartphones which are freely available with citizens. Citizens' engagement increases the levels of transparency, accountability, and the trust between the government and the citizens. However, citizens are usually reluctant to engage, and they may lack the technical background and skills needed for such engagement. To promote their participation there should be a simple and attractive engagement model that is suitable for non-skilled citizens. Existing engagement models can be broadly classified into two main categories: co-design and crowdsourcing. Co-design means cooperate in creating solutions, applications and services. In this approach, the government opens its data to citizens while the citizens create services and solutions to benefit from these data. On the other hand, crowdsourcing involves taking a large task and breaking it into small, welldefined tasks for a crowd of people to complete. In this approach citizens act as a source of data by using their mobile phones capabilities like cameras and GPS to collect data and images, provide feedback and raise issues about their city to be used in policy formation and governance. In this paper, a crowdsourcing web-based wiki system "Riyadh Wiki Information and Complaining System" is proposed to engage citizens in Riyadh city in Saudi Arabia. Crowdsourcing approach has been selected as it is the most scalable approach that does not require highly skilled citizens. Using this approach, the huge task of data collection is divided into smaller tasks to be carried out by the crowd. Co-design approach has been supported also by allowing the skilled citizens toadd new features and new services to the system. Web-applications are easy to use by non-skilled citizens while wiki systems enable users to develop the website and to share information in a collaborative low-cost way [5, 6]. As defined in [7], "a wiki is a collaborative web site whose content can be edited by visitors to the site, allowing users to easily create and edit web pages collaboratively". It is a dynamic flexible shared web site that allows users to add contents, links, categories, and add data to be shared by other users.

"Riyadh Wiki Information and Complaining System" is an initiative for the smartness of Riyadh city and presents a model of engagement, where the citizens can engage in the smartness of their city by publishing Riyadh issues and data about specific sectors such as health and education sectors with the ability to addnew sectors and new information to the system. In other words, the system will allow citizens in Riyadh to act as sensor nodes and sources of data to support the government and to improve their city. Wikia tool has been selected for the system implementation as it is a free open source tool with useful features to reduce the development effort.

This paper is structured as follows: section 2 presents related work on literature. Section 3 describes the new system. Evaluation is provided in section 4, and finally, conclusions are presented in section 5 .

\section{RELATED WORK}

Several cities around the world have been transformed to smart cities. Dubai, Trikala, Barcelona, Blacksburg Electronic Village, Amsterdam, Singapore [8], Rio de Janeiro, Dubuque, Bornholm, and Songdo IBD [9] are examples of cities that transformed to smart cities. To achieve the visions 
International Journal of Managing Information Technology (IJMIT) Vol.10, No.2, May 2018

of smart city, different models of engagements and different initiatives have been developed. These engagement models can be broadly classified into two main categories: co-design and crowdsourcing.

Co-design approach is based upon engaging citizens in the design, development, and evaluation of services and applications. Several works based on the co-design approach have been developed. Álvaro Oliveira and Margarida Campolargo in [10]propose the use of technologies as enablers to connect and engage government and citizens. To investigate the Human Smart Cities concept, the authors presented MyNeighbourhood platform as an example. As described by the authors "The ultimate aim of MyNeighbourhood is to create a momentum and dynamics leading multiple urban neighbors across Europe to use the MyNeighbourhood Platform to reconnect with one another, share new ideas, create new ways of interacting and help to make their lives 'smarter' [10]". MyNeighbourhood platform is based on the collaboration and co-design between the citizens to create smart solutions that focus on the human rather than technology. They used games technology and gamification method to encourage the citizens to use the platform and to invent new services.

MyNeighbourhood project has been used in different cities like Aalborg, Birmingham, Lisbon, and Milan; and the services provided for each city cover different sectors such as health care and transportation. The project highlights the advantages for the co-design approach as a low cost scalable approach that does not need huge infrastructure.

Carina Veeckman and Shenja van der Graaf in [11] also discuss the importance of the co-design and the engagement of the citizens in the smartness of a city. They view the city as a living laboratory in which the government open its data and the citizens collaborate in the invention of new services. The paper presents the collaboration in producing smart city services between different actors in the living lab environment; those actors are research organizations, citizens as users in providing the feedback, and developers in co-design process. The living lab provides templates that the citizens can use to develop smart services by accessing the open data. Twentyfive developers were selected in four cities to use the system and feedback from logging, questionnaires and interviews was collected. However, the initial results showed that the developers did not use the application templates. Consequently, a tool has been created to allow users to combine various datasets in a city and to build basic applications without writing single line of code. Several applications and services have been developed using the living lab environment. As an example, the "City Navigator App" application is currently used in different cities in Europe [11].

Co-design is a low-cost efficient solution, but it has many limitations. The previous examples show how the co-design approach can produce useful smart city services and highlight the difficulty to engage citizens in the co-design process. As described above, engagement of citizens can be improved if appropriate tools are provided. However, the level of citizens' involvement depends on the capabilities of the tools and the personal skills of citizens. Also, citizens may be reluctant to use these tools which limits its applicability. This limits the scope and number of citizens who would participate in the delivery of the smart city services.

On the other hand, crowdsourcing approach is based upon collecting data, feedback and issues relevant to a city by its citizens. Consequently, huge data can be collected about the different sectors easily in a cheap way. Karim Benouaret, Raman Valliyur-Ramalingam, and François Charoy [12] developed a platform (CrowdSc) that enables citizens to participate with the 
International Journal of Managing Information Technology (IJMIT) Vol.10, No.2, May 2018

government in the data collection, selection, and evaluation tasks. This framework consists of three models: input, task and output models. Citizens enter their queries using the input model and get the answers through the output model. The task model processes the queries and divides them into smaller tasks by using different strategies. After that the data is collected from the crowd and after processing and cleaning, the results will be returned to the citizens.

Another framework following crowdsourcing approach is a mobile sensing application presented in [13]. This framework is called Gather-Share-Govern (GSG) and consists of three layers and three plans. The first one is the gather plan that uses the mobile phone sensors for gathering data. The second is the share plan for the mobile network infrastructure and communication. The third is the govern plan for the analysis of the data.

The authors in [14] presented an open source platform for citizen engagement called ImproveMyCity. The role of citizens is reporting to government by submitting issues about their neighborhood such as broken street light. ImproveMyCity is available as a web-system and as a mobile application where citizens are able to add comments, vote, in addition to reporting their neighborhood issues. The different issues will be automatically directed to the appropriate department in the government which will process and fix these issues via back-end infrastructure. Citizens are able to track the status of their submitted issues.

Crowdsourcing is a more scalable low-cost approach that improves the government transparency and trust by considering citizens as a source of information. However, easy to use tools to share data, images and feedback should be provided to encourage citizens to participate. Web applications and social networks are the most useful and easy to use tools that any citizen can use without a need to particular skills. However, most portal systems and websites are limited and cover specific sectors only.

To increase the scope of engagement so that it can cover large number of sectors, Wiki systems can be used, so that the citizens rather than the government will carry out the web-development process. In this paper, we propose a scalable Wiki system for citizens' engagement in Riyadh city. This system exploits the wide spread of mobile devices with GPS, cameras and many sensors as a major source of information. Moreover, skilled citizens can add new functionalities and services to the system so it can be considered as a hybrid engagement model based on both crowdsourcing and co-design approaches.

\section{A NeW RiYAdH Wiki SYSTEM}

"Riyadh Wiki Information and Complaining System" is an initiative for the smartness of Riyadh city. It presents a hybrid model of engagement, where the citizens can engage in the smartness of their city by publishing Riyadh issues and data about different sectors such as health and education sectors; in addition, citizens can add new features, functionalities and even new sectors to the system. In other words, the system follows the crowdsourcing approach by allowing citizens to act as sensor nodes and sources of data to support the government and to improve their city. It also follows the co-design approach by being an open source platform that allows citizens to cooperate to build the system and add new features and functionalities to it.

The system aims at enhancing citizens' life quality and solving many governmental issues in a cheap and easy way. Using it, the citizens will be aware of the different Riyadh issues, and will 
International Journal of Managing Information Technology (IJMIT) Vol.10, No.2, May 2018

be encouraged to participate in publishing the issues. As a complaining system, it adds the following benefits [15]:

- Opening a connection between the people and the governmental agencies, where people can share their issues and the agency can listen to them.

- Improving agencies' services by hearing the people issues and fixing them.

- Increasing the level of people satisfaction.

- Saving agency time, by discovering the problem earlier from the people and fixing them.

- Saving agency money, by taking a good decision that can meet people needs, instead of taking wrong decision that cost a lot to fix them.

In other words, the system aims at solving the previously mentioned government issues: transparency, trust on the government, decision-making, and accountability in a cheap way as follows:

- Transparency: there will be a connection between the citizens and the government, so the citizens can know everything happen in their government and in their city.

- Trust: The citizens can report their issues to the government, and appropriate actions from the government side will be taken to solve these issues. This will increase the trust of citizens in their government

- Decision making: there will be an interaction between the government and the citizens to know their real needs and taking the right decisions that can meet these needs, so this also will reduce the costs on the government that resulting from the inaccurate decisions, thus accelerate and improve the government decision-making process.

- Accountability: where each government agency performance and services can be evaluated by citizens via providing feedback, voting...etc. thus raising the accountability level.

\subsection{SYSTEM FUNCTIONALITIES}

"Riyadh Wiki Information and Complaining System" is a web-based system where citizens can discuss, add and share data and issues in the city of Riyadh in order to publish important information, fix issues and improve their city. The home page of the system is shown in Fig 1 . The main functions of the system are:

- Manage Sector - contribute on building the system by adding new sectors or voting on building new sectors to add them.

- Manage Information: view/add/delete/update information in the different sectors.

- Manage Complaint: view/add/delete/update complains relevant to the different sectors.

- Add photos and/or videos that support the information or complains.

- Add location: use Riyadh map to specify locations related to the information or complains, and Fig 2 presents Riyadh map.

- Add comments to the information or complains added by other citizens.

- Share information to specific government agents and/or other citizens on social networks. This will ensure the reaches of information to a large segment of the society; it will also encourage other citizens to participate in the system.

- Share complaints on any sector with the government on the application or via social networks specifically twitter which is the cheapest and fastest channel of communication. 
International Journal of Managing Information Technology (IJMIT) Vol.10, No.2, May 2018

- General search: search about any information on any sector on the system or ask other citizens about any information on any sector.

- View twitter timeline: view latest news or information on any sector on twitter timeline.

- Voting: vote for adding new sector.

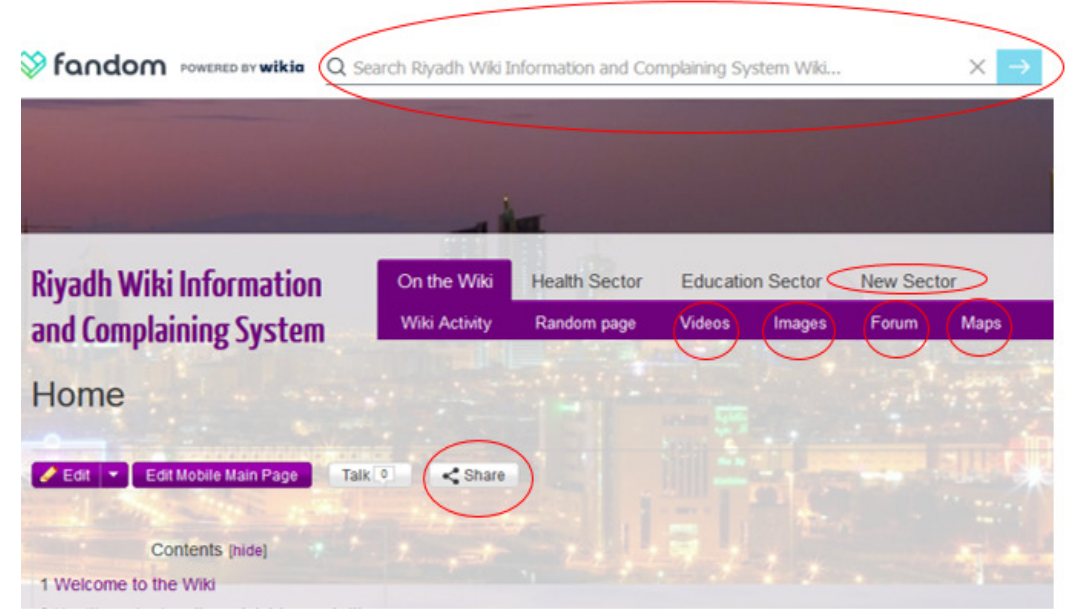

Fig 1 System home page

\subsection{SYSTEM DEVELOPMENT}

To increase the scope of engagement so that it can cover large number of citizens and large number of sectors, the system has been developed using Wiki tools so that the citizens rather than the government will carry out the web-development process. Using Wiki, citizens can add new sectors and share data, complains, and feedback about the different sectors in the city, and the different services that the government provides. Wikis have several benefits [16-18] by allowing anyone to edit and share the content, allowing the creation of a content in a collaborative way, using simple version of HTML as a markup scheme, easy linking between the web pages, where the web page titles avoid the spaces in naming to allow faster creating, editing, and linking the web pages and finally the web content is "ego-less, time-less, and never finished" [16].

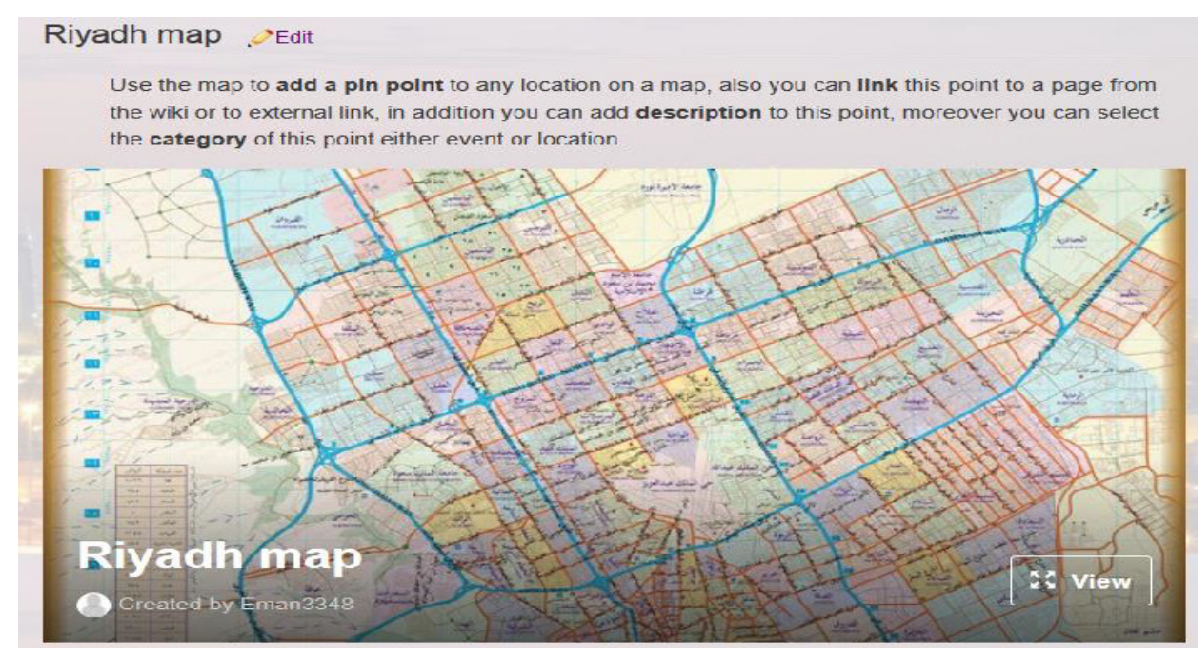

Fig. 2 Riyadh map 
International Journal of Managing Information Technology (IJMIT) Vol.10, No.2, May 2018

Riyadh Wiki has been developed using the Wikia tool [19], which is free tool that gains its revenue from the advertisements. The used markup language on Wikia is Wikitext, in addition to some HTML tags and CSS [20]. Wikia tool has been selected after in-depth analysis of several available tools and a comparison between $25 \mathrm{Wiki}$ tools in terms of different featured needed for the system. Wikia was selected because it covers most of required features including being a free open source tool, mobile friendly and the support of Arabic and English languages.In addition, Wikia has features or services that are useful on building the system such as Polls, Top 10 lists, and Achievements.

The system has been developed with many features that encourage and facilitate the citizens' participation. Based on the citizen's interest, he/she can use different ways to add information, e.g. as text, images or videos. Image gallery can be accessed from the navigation bar as an easy way to attract citizens to specific topics using attractive images. The widespread of social networks has been exploited to attract more users to the system.

The system was initially developed with two main sectors: education and health in both Arabic and English languages. Citizens can add information by adding new pages to each sector and/or adding content to these pages. They also have the ability to edit these pages or delete them. In addition, citizens can just update the existing pages on the system on each sector by adding content to them. There are two types of interactivity tools available for the citizens to add ideas, issues or questions: Discussions and Forums. Discussions allow citizens to add, update and delete information, comment on any topic, or rate the topic by using upvote. Citizens can also share the topic on Twitter, Facebook, Reddit, or Tumblr. Forums allow citizens to add, update and delete information, comment on any topic, or rate the topic by using kudos and preview information before posting it. They also provide notification service and allow users to add link, photo, pdf files, or video to their information.

Riyadh map is used to allow citizens to add locations on a map to their information, events and complains, or to describe locations and relate them to pages on the system or external links. The map has been developed using map extension on Wikia, where this extension can be used by citizens to propose ideas in a smart and creative manner as the system allows users to invent maps that serve their ideas, by drawing images and link each part on the image to pages inside or outside the system.

The system exploits also useful features of Wikia like voting systems and achievements tool. The system provides a Top 10 list that can be used to support the government decision making process by allowing citizens to vote in any topic. Currently, it is used to select among different sectors to be added to the system. Achievement tool is also a useful feature to encourage the citizens to use the system by earning points for every contribution they made to the system. This can be used by the government to provide annual rewards for the active citizens thus promoting citizens' participation.

\section{Evaluation Of The System}

In this section, initial evaluation of "Riyadh Wiki Information and Complaining System" is presented. The system emphasizes the importance of people's interactions and participation to support the government and to achieve smart city vision. As the success of the system is based on contributions of users on building the content of the web pages, evaluation of the system will be 
International Journal of Managing Information Technology (IJMIT) Vol.10, No.2, May 2018

based upon e-participation assessment, web accessibility evaluation and the web usability evaluation.

\subsection{E-PARTICIPATION ASSESSMENT}

E-Participation is a new means of participation and a subset of e-governance and e-democracies [21]. It is based on modern ICT supported platform to facilitate the participation in government and governance [21].

The assessment of the success of e-participation in the system is based on the existence of eparticipation features that are provided by United Nations e-Government Survey [22]. Results of e-participation assessment are shown in table 1.

As shown in the table the first and second features do not exist currently in the system. However, they can be added in future if the government adopt the system and run it. All other features are available on the system.

\subsection{Web ACCESSIBILITy Evaluation}

Web accessibility means that "people with disabilities can perceive, understand, navigate, and interact with the Web, and that they can contribute to the Web" [23]. Web accessibility also includes older people with changing capabilities due to aging [24].

Table 1 e-participation assessment.

\begin{tabular}{|c|c|c|}
\hline no & The features & $\begin{array}{c}\text { The } \\
\text { system }\end{array}$ \\
\hline 1 & $\begin{array}{c}\text { "Existence of archived information } \\
\text { (policies, budget, legal documents etc.) } \\
\text { related to education, health, finance, } \\
\text { social welfare, labour information and } \\
\text { environment [22]". }\end{array}$ & No \\
\hline 2 & $\begin{array}{c}\text { "Existence of datasets on education, } \\
\text { health, finance such as government } \\
\text { spending, social welfare, labour } \\
\text { information and environment [22]". }\end{array}$ & No \\
\hline 3 & $\begin{array}{c}\text { "Access to government website in } \\
\text { more than one official national } \\
\text { language [22]". }\end{array}$ & Yes \\
\hline 4 & $\begin{array}{c}\text { "Availability of social networking } \\
\text { features [22]". }\end{array}$ & Yes \\
\hline 5 & $\begin{array}{c}\text { "Presence of e-consultation } \\
\text { mechanisms for the six sectors: } \\
\text { education, health, finance, social } \\
\text { welfare, labour information and } \\
\text { environment [22]". }\end{array}$ & Yes \\
\hline 6 & $\begin{array}{c}\text { "Availability of tools in order to obtain } \\
\text { raw (non-deliberative) public opinion } \\
\text { for public policy deliberation such as } \\
\text { online forums, media tools, polls, } \\
\text { voting tolls and petition tools [22]". }\end{array}$ & Yes \\
\hline
\end{tabular}


International Journal of Managing Information Technology (IJMIT) Vol.10, No.2, May 2018

\begin{tabular}{|c|c|c|}
\hline 7 & $\begin{array}{c}\text { "Presence of e-decision-making tools } \\
\text { for the six sectors: education, health, } \\
\text { finance, social welfare, labour } \\
\text { information and environment [22]". }\end{array}$ & Yes \\
\hline
\end{tabular}

A manual accessibility testing that focuses on citizens with motor disability, and citizens with visual disability has been conducted:

- For citizens with motor disability:

Navigate without a mouse technique is used on this testing, where for citizens with motor disability accessing the web content by using keyboard, because using the mouse is difficult for them [25].

On this test, Tab key used to navigate, shift key with Tab key to back, and Enter key to do action [25]. As a result of this testing, all pages of the system are accessed successfully without using a mouse, so the system is accessible for citizens with motor disability.

- For citizens with visual disability:

"Visual disabilities range from mild or moderate vision impairments in one or both eyes ("low vision" or "partial sight"), to substantial and uncorrectable loss of vision in both eyes ("blindness") [26]".

Zoom a page and enlarge text technique is used on this testing, where citizens with visual disability enlarge text on the page to read it clearly [25].

On this test, Ctrl key with plus key are used to enlarge the content, Ctrl key with minus key is used to make it smaller, and Ctrl key with number zero to return it to default state [25]. As a result of this testing, the content of all pages of the system zoom in and out on the range 150\%$200 \%$ and it is still readable, so the system is considered accessible for citizens with visual disability.

\subsection{WEB USABILITY EVALUATION}

ISO defines usability as the "extent to which a product can be used by specified users to achieve specified goals effectively, efficiently and with satisfaction in a specified context of use" (in ISO 9241-11) [28]". To ensure the usability on our system, the following conditions should be satisfied:

1. The system must operate on any device: laptop, smartphone, or tablet.

2. The system must be accessible anytime and anywhere.

3. The system must be available on different languages.

4. The system must be free of charge.

5. As the content of the system will be created by the citizens, the system should have usability features that will facilitate their work.

6. Complaining systems must have features to facilitate adding and reinforcing complains.

By evaluation the system against these conditions we can conclude that accessing the system can be achieved via different channels: Web site for laptop, Web site with mobile friendly feature for smartphone and tablet, and Mobile view for smartphone and tablet (A request to Wikia has been submitted to). This satisfies condition 1. Regarding condition 2, citizens will just need to have 
International Journal of Managing Information Technology (IJMIT) Vol.10, No.2, May 2018

internet access to access the system anytime and anywhere. For condition 3, the system supports both Arabic and English languages. The system is also free which satisfies condition 4. Regarding condition 5, several features facilitate the citizens work such as: Section Editing, Page Templates, Double-Click Edit, Toolbar, and Access Keys [28]. In addition, for editing we have two types of editors that can ensure all citizens with their different knowledge levels can participate on creating the content, which are Visual editor (What You See Is What You Get) Editing, and Classic editor. Finally, for condition 6, the citizens can add their complaints as a text, then they can reinforce their complaint by adding video, image, location, or pdf file.

Also, to ensure that citizens can use the system and carry out the different functions in an easy manner, a number of citizens of different ages and different education background in Riyadh city test the system and feedback has been collected from them. The test includes measuring the time needed to carry out the main functions of the system (Add/Delete sector, Add/Update/Delete information, Add/Update/Delete complain, General search, Add photo/video/comment/location, share on social networks, Vote). Also, feedback about difficulty or problem faced was collected. Overall, the results of the survey show that the system is easy to use by citizens regardless of the education level though some functions took more time by less educated citizens. An example of the time needed to add information to the system is shown in Fig 3 where time is expresses in seconds.

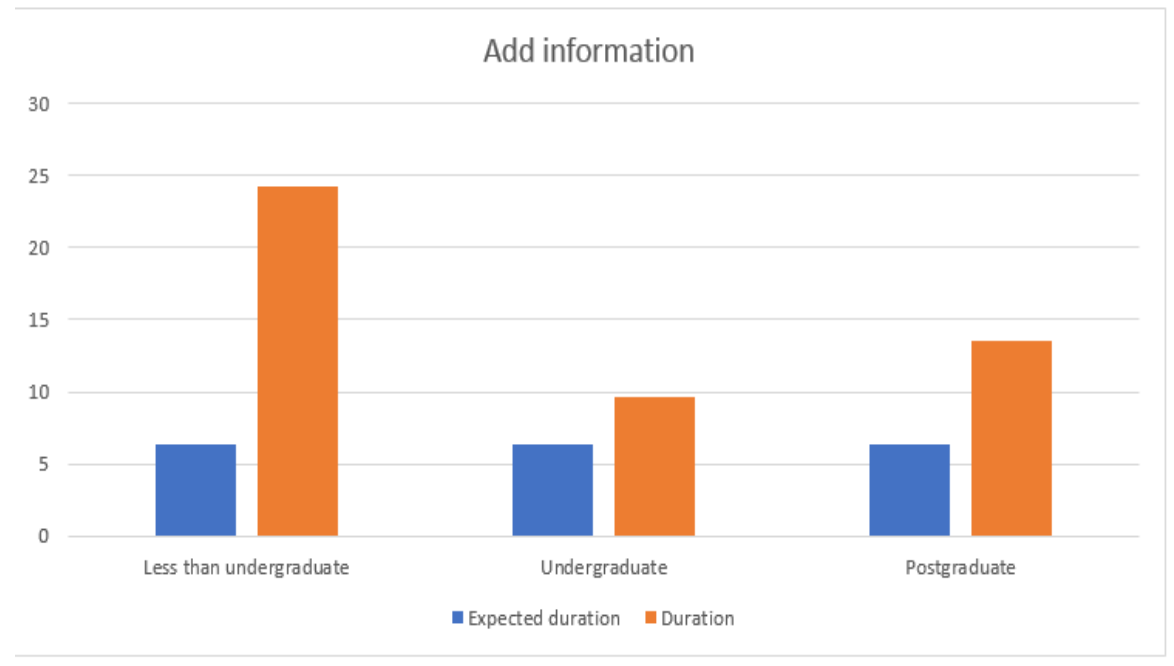

\section{Conclusion}

Fig. 3 Time needed to add information

In this paper, we present "Riyadh Wiki Information and Complaining System" to promote the engagement of Riyadh citizens with the government to achieve the vision of a smart Riyadh city. The aim of the system is to solve many governmental issues like transparency, trust, decision making and accountability in a cheap and easy way. The system follows a hybrid approach where, following the crowd source approach, citizens act as sensor nodes that provide data and information about their cities. On the other hand, following the co-design approach, skilled citizens can develop new functionalities and services to the system. The system is developed as a web application so non-skilled citizens can use it easily. It is a Wiki system, where citizens rather than the government carry out the web-development process. The system supports both Arabic and English language and exploits the widespread of social media to attract more citizens. It allows different presentations of information as text, images, video and maps and provides voting and reward systems to encourage citizens' participation. The system has been evaluated using e- 
International Journal of Managing Information Technology (IJMIT) Vol.10, No.2, May 2018

participation assessment, web accessibility assessment, and web usability assessment. Results show that the system is easy to use by citizens regardless of their background and skills. The system can be enhanced by adding audio features to it. Also, the government can provide their data and statistics for the citizens to use and to create new services based on available data.

\section{REFERENCES}

[1] Mishra M K (2013) Role of Technology in Smart Governance:'Smart City, Safe City'. https://ssrn.com/abstract=2310465 or http://dx.doi.org/10.2139/ssrn.2310465

[2] Pham L (2014) Resident Engagement as a necessary component for Smart City Programmes. IERC. http://www.ierc.ie/wp-content/uploads/2014/07/IERC-Resident-Engagement-Whitepaper.pdf

[3] Esri (2012) “citizen engagement C". https://www.esri.com/library/brochures/pdfs/gov20-citizenengagement.pdf.

[4] Castelnovo W.; Misuraca G.; Savoldelli A. Citizen's engagement and value co-production in smart and sustainable cities.International Conference on Public Policy. 2015, pp. 1-16.

[5] Alexander B. Web 2.0: A New Wave of Innovation for Teaching and Learning, EDUCAUSE Review, 41, 2006, pp.32-44.

[6] Louridas P. Using wikis in software development, Software, 23, 2006, pp.88-91.

[7] Chao, J. Student project collaboration using Wikis. Proceedings of the 20th Conference on Software Engineering Education and Training (CSEE\&T 2007), Dublin, Ireland. 2007.

[8] Anthopoulos, L.; Fitsilis, P. Exploring architectural and organizational features in smart cities. Advanced Communication Technology (ICACT) 16th International Conference, 2014, pp. 190-195.

[9] Naphade M, et al. Smarter Cities and Their Innovation Challenges, Computer, 44, 2011, pp.32-39.

[10] Oliveira, A.;Campolargo, M.From Smart Cities to Human Smart Cities.System Sciences (HICSS) 48th Hawaii International Conference, 2015, pp. 2336-2344.

[11] Veeckman, C.;Van der Graaf, S.The city as living labortory: A playground for the innovative development of smart city applications.Engineering, Technology and Innovation (ICE) International ICE Conference, 2014, pp.1-10.

[12] Benouaret K, Valliyur-Ramalingam R, Charoy F. CrowdSC: Building Smart Cities with Large-Scale Citizen Participation, Internet Computing, 17, 2013, pp.57-63.

[13] Balakrishna, C. Enabling Technologies for Smart City Services and Applications.Next Generation Mobile Applications Services and Technologies (NGMAST) 6th International Conference, 2012, pp.223-227.

[14] Tsampoulatidis, I.; et al. ImproveMyCity: an open source platform for direct citizen-government communication. Proceedings of the 21st ACM international conference on Multimedia, 2013, pp. 839-842.

[15] The Local Government Ombudsman, Devising A government Complaint System. http://ombud.alaska.gov/complaint-system.pdf. 
International Journal of Managing Information Technology (IJMIT) Vol.10, No.2, May 2018

[16] Lamb B. Wide open spaces: Wikis, ready or not, EDUCAUSE Review, 39, 2004, pp.36-48.

[17] Wagner C. Wiki: A technology for conversational knowledge management and group collaboration, The Communications of the Association for Information Systems, 2004, 13, pp.58.

[18] Parker R, Chao J. Wiki as a teaching tool, Interdisciplinary journal of knowledge and learning objects, 2007, 3,pp.57-72.

[19] Wikipedia, Wikia. https://en.wikipedia.org/wiki/Wikia.

[20] FANDOM, WIKIA, Help:HTML. http://community.wikia.com/wiki/Help:HTML.

[21] Islam S. Towards a sustainable e-Participation implementation model, European Journal of ePractice, 2008,5 .

[22] United Nations E-Government Survey (2014) E-Government for the future we want. United Nations Department of economic and social affairs.

[23] Vessey I, Ramesh V, Glass R. A unified classification system for research in the computing disciplines, Information and Software Technology, 2005, 47, pp.245-255.

[24] W3C (2005) Introduction to Web Accessibility. https://www.w3.org/WAI/intro/accessibility.php.

[25] NCDAE, Identifying Web Accessibility Issues.

http://ncdae.org/resources/cheatsheets/accessibility.php.

[26] W3C (2017) Diversity of Web Users. https://www.w3.org/WAI/intro/people-useweb/diversity\#visual.

[27] W3C (2010) Accessibility, Usability, and Inclusion: Related Aspects of a Web for All A. http://www.w3.org/WAI/intro/usable.

[28] Wiki Matrix. http://www.wikimatrix.org/. 